The tobacco industry claims that its current low tar cigarettes are less dangerous than the untipped high tar cigarettes that were popular a generation ago. Almost certainly low tar cigarettes do cause less lung cancer-but the college report emphasises that there is no evidence that the smoking of cigarettes of reduced tar or nicotine yield reduces deaths from coronary heart disease, which numerically is the greatest killer among the smoking related diseases. Just how complex are the effects on heart disease of the constituents of cigarette smoke is shown in the paper by Professor Geoffrey Rose and his colleagues at $\mathrm{p} 1583$. In its futile pursuit of a safe cigarette the tobacco industry is chasing a will o' the wisp.

The college report also draws together material on two topics that have come into the public eye recently: passive smoking and smoking in the Third World. Even low concentrations of smoke may affect the exercise tolerance of patients with coronary heart disease and chronic obstructive lung disease, and while the link between passive smoking and lung cancer remains disputed no one can doubt the irritative effect of smoke on the eyes, pharynx, and psyche of non-smokers. (Indeed, the lack of any such intrusion into other people's environments is one factor that has influenced doctors addicted to nicotine to take their tobacco as snuff.)

Its promotion of tobacco growing and smoking in Third World countries is the clearest possible evidence of the callous indifference to health shown by the international tobacco industry. Advertising of cigarettes in much of the developing world is "blatant and forceful," says the college report.

For years now the $B M \mathcal{F}$ has argued that further advance in the control of smoking related disease must come from government action. ${ }^{2-6}$ If its title means anything the Department of Health has a duty to produce a coordinated plan taking in a ban on advertising, changes in taxation, restrictions on smoking in public places and at work, and control of tobacco sponsorship of sport and culture. The college report will be supported by all doctors in its call for such action-and in its argument that the British government has "a responsibility to control smoking not only out of concern for the health of its own people but in full awareness of its exemplary role towards developing countries."

'Royal College of Physicians. Health or smoking? London: Pitman Medical, 1983.

2Anonymous. Menace of smoking. Br Med $\mathcal{f} 1967$;iii:753-4.

${ }^{3}$ Anonymous. Cowardice about smoking. Br Med f $1971 ;$; 683.

4 Anonymous. The cowardice continues. Br Med f 1977;i:1428-9.

'Anonymous. Ten years of ASH. Br Med f $1981 ; 282: 340$.

${ }^{6}$ Anonymous. Smoking still kills. Br Med f 1982 ;285:1295-6.

\section{Choice of insulin}

The aim of any insulin regimen is to achieve the best possible blood glucose control without evident swings to high or low extremes, and especially avoiding problems from hypoglycaemia. Short acting soluble insulin and medium acting isophane and zinc suspensions are the main types of insulin in use. They are normally used singly or in combination in regimens which vary from once to four times daily. The long acting zinc preparation, ultratard insulin, is sometimes of additional value, but the use of protamine zinc insulin is declining rapidly with the development of better formulations. Once the changeover to $100 \mathrm{unit} / \mathrm{ml}$ insulin has been completed all insulins will in varying degrees be "purified." Insulins are made from beef or pig carcases, and their structure differs from that of human insulin by three and one amino acids respectively. Recently, preparations with the structure of human insulin have been manufactured either by genetic manipulation of bacteria or by laboratory manipulation of porcine insulin. "Human" insulin derived from bacteria by the brilliant new method of recombinant DNA technology is described by the epithet chain recombinant DNA bacteria (crb), and the semisynthetic human insulin derived from pig insulin is described as enzyme modified pork (emp).

Insulins from different sources may have different effects at the site of injection, on antibody formation, and vary in their duration of action, and so these aspects must be considered in the choice of an insulin preparation.

Fat atrophy or a fatty tumour may develop at the site of injection, although atrophy is rarely seen now. It may have an immunological basis, and this might explain why it is seldom seen in patients taking the purer insulin preparations. ${ }^{1}$ Fatty tumours occur if repeated injections are given into a limited area, and these are still seen with the purified insulins. Localised insulin allergy is rarely a problem and is even less likely to occur with purified insulins. The very rare phenomenon of generalised insulin allergy is associated with high concentrations of insulin specific $\mathrm{IgE}^{2}$ and may follow exposure not only to beef or purified pork insulins but also to human insulins. Cases have, however, been either in atopic individuals or in people with evidence of previous exposure to conventional insulins. ${ }^{3} 4$ Human insulin preparations may confer an advantage. Zinc and protamine components of insulin may also be responsible for hypersensitivity phenomena.

Insulin binding immunoglobulin antibodies develop in response to regular subcutaneous injection of most, if not all insulin preparations. Antibody formation is provoked not only by impurities, especially proinsulin (now largely eliminated from "purified" insulins), but also by insulin derivatives (desamido insulin, arginyl insulins, insulin ethyl esters) and by the complexed insulin preparations with a longer duration of action. ${ }^{5}$ Human insulins are thus potentially antigenic, but less so than porcine insulins. ${ }^{7}$ Beef insulins are more antigenic than either human or porcine insulin preparations. Antibody titres gradually decrease over several months after changing from beef to pork or pork to human insulins. ${ }^{8}$

Insulin binding antibodies are not known to have any harmful effects, and they are not responsible for diabetic complications which frequently occur in patients who have never been treated with insulin. Insulin resistance is exceptionally rare whichever insulin preparation is used. Prolongation of the action of insulin by the presence of insulin antibodies might theoretically be advantageous and, though in practice this effect is probably unimportant, some of the human insulin preparations do appear to have a shorter action than similar animal preparations.

Pharmacokinetic studies of human insulin preparations injected intravenously or subcutaneously into normal and diabetic people generally show no differences from the effects of porcine insulin. ${ }^{6}$ Clinical experience of human insulins shows no important differences in blood glucose control when compared with that during treatment using animal insulins, ${ }^{9}$ and two new studies describing the use of human semisynthetic insulins are reported on pp 1578 and 1580. Higher fasting blood glucose concentrations have been described with both kinds of human insulins, suggesting that they have 
a shorter duration of action than conventional insulins. Because some patients are perhaps also prone to early hypoglycaemia it has been suggested that less short acting and more intermediate acting insulin may be needed. No important dose differences have been reported, however, though if anything slightly larger doses of human than porcine insulin may be required. There is no evidence that blood glucose control is improved by using human insulins.

At present, the clinical effects of human insulins are not, therefore, appreciably different from those of conventional animal insulins. Indications for their use are limited to a possible advantage in preventing those rare cases of insulin allergy or antibody mediated insulin resistance. ${ }^{10}$ In terms of cost, the cheapest insulins (U100) are purified beef preparations; human recombinant insulin is comparable in price to the purified pork insulins, while human semisynthetic insulins are inevitably much more expensive. There is then no reason, either clinical or economic, for routinely transferring diabetics to human insulins. The choice at the onset of diabetes must be determined by the considerations presented here and tempered by the need to know the results of long term trials which are now in progress.

P J WATKINS

Consultant Physician,

Diabetic Department,

King's College Hospital,

London SE5 9RS

${ }^{1}$ Reeves WG, Allen BR, Tattersall RB. Insulin-induced lipoatrophy: evidence for an immune pathogenesis. $\mathrm{Br}$ Med 7 1980;280:1500-3.

2 Falholt K. Determination of insulin specific IgE in serum of diabetic patients by solid-phase radioimmunoassay. Diabetologia $1982 ; 22: 254-7$.

${ }^{3}$ Wiles PG, Guy R, Watkins SM, Reeves WG. Allergy to purified bovine, porcine, and human insulins. Br Med $\mathcal{F} 1983 ; \mathbf{2 8 7}: 531$.

${ }^{4}$ Altman JJ, Pehuet M, Slama G, Tchobroutsky C. Three cases of allergic reaction to human insulin. Lancet 1983;ii:524.

${ }^{5}$ Hansen B, Lernmark A, Nielsen JH, Owerbach D, Welinder B. New approaches to therapy and diagnosis of diabetes. Diabetologia 1982 $22: 61-7$

${ }^{6}$ Home PD, Albert: KGMM. Human insulin. Clin Endocrinol Metab $1982 ; 11: 453-83$.

Fireman P, Fineberg SE, Galloway JA. Development of IgE antibodies to human (recombinant DNA), porcine, and bovine insulins in diabetic subjects. Diabetes Care 1982;5, suppl 2:119-25.

* Fineberg SE, Galloway JA, Fineberg NS, Rathbun MJ. Immunologic improvement resulting from the transfer of animal insulin-treated diabetic subjects to human insulin (recombinant DNA). Diabetes Care $1982 ; 5$, suppl $2: 107-13$

${ }^{9}$ Clark AJL, Adeniyi-Jones RO, Knight G, et al. Biosynthetic human insulin in the treatment of diabetes. A double-blind crossover trial in established diabetic patients. Lancet 1982 ;ii:354-7.

${ }^{10}$ Maneschi F, Fineberg SE, Kohner EM. Successful treatment of immunemediated insulin resistance by human insulin (recombinant DNA). Diabetes Care 1982;5, suppl 2:175-9.

\section{Gut peptides and the control of food intake}

The acquisition, preparation, and eating of food have preoccupied man for centuries, but only relatively recently have appetite and the regulation of food intake been studied systematically. The past decade has seen an increasing (and fashionable) interest in nutrition in all its aspects. Obesity has become an alarming problem in many countries, and gastrointestinal hormones have become a growth topic for research in several disciplines, one of which concerns their potential role in appetite regulation.
The control of food intake is extraordinarily complex, with psychological factors (taste, smell, visual appeal), conditioned reflexes, and hypothalamic "centres" all contributingtogether with potential messages to the brain from vagal afferents responding to gastric or intestinal distension, from absorbed products of food digestion, and possibly also from chemical messengers (which may include gastrointestinal hormones released from the gut). Clearly with such diverse mechanisms, isolating individual influences for investigation without interfering with other factors is likely to be difficult. The main central control areas lie in the hypothalamus. The lateral hypothalamus appears to be concerned with hunger and the initiation of feeding and the ventromedial hypothalamus with the inhibition of feeding - the "satiety centre." Relatively little is known of the large number of tracts which interconnect with these regions or of the various neurotransmitters which mediate their impulses. If all the hypothalamic assembly is taken as a single unit, however, then messages may be assumed to reach it either by way of the nervous system or via the bloodstream.

The idea that gastrointestinal hormones released after a meal might reach the brain and stimulate the satiety centre was derived from the observation that some form of message inhibiting feeding comes from the stomach and small intestine when they contain food. Part of the stimulus seems to be physical and due to distension, ${ }^{1-3}$ and this may be enough to explain why bulky meals satisfy hunger better than those of an equal energy content of refined carbohydrate. ${ }^{2}{ }^{4}$ Foodstuffs are more powerful than bulk alone in promoting satiety, however, and vagotomy only incompletely abolishes the satiating effect of food in the stomach or small intestine, suggesting that hormonal factors may also play a part. ${ }^{56}$ Food placed in an isolated transplanted stomach elicits satiety, ${ }^{7}$ and the satiating effect of food in the small intestine is, if anything, greater than that of food in the stomach.

In 1973 the gastrointestinal peptide hormone cholecystokinin-pancreozymin (which is released when food enters the small intestine) was shown to inhibit feeding when injected intraperitoneally in rats. ${ }^{8}$ Since then numerous studies have shown that injections or infusions of this hormone decrease food intake in both animals and man. ${ }^{8-16}$ The problem is whether these effects are physiological or merely a pharmacological (though nevertheless interesting) effect of large doses of cholecystokinin, as suggested by several dissenting voices. ${ }^{17-19}$

The present debate is in many respects very similar to that which took place some years ago over the role of gastrin in regulation of pressure in the lower oesophageal sphincter. The argument goes as follows: lower oesophageal sphincter pressure rises after a meal; gastrin is released by a meal; injections or infusions of gastrin produce a rise in lower oesophageal sphincter pressure; therefore the observed rise in lower oesophageal sphincter pressure after a meal is due to the gastrin released by that meal. This debate is 10 years old and still not convincingly concluded, but a consensus view might now be that gastrin may have a relatively small effect but is only one of many factors which influence lower oesophageal sphincter pressure. Interested readers may follow the debate in retrospect in a series of papers and sometimes entertaining correspondence. ${ }^{20-24}$

The case for cholecystokinin as a satiety hormone seems much weaker than was that of gastrin as an oesophageal sphincter tonic. Cholecystokinin would presumably have to reach the hypothalamus (or some part of the brain in connection with it) and so would have to cross the blood-brain barrier. This would seem to be an unnecessarily difficult arrangement, 